\title{
PERFORMANCE EFFECTS OF COOPERATION AND COMPETITION INTENSITY IN INTERNATIONAL EDUCATION FOR TRADITIONAL CHINESE MEDICINE
}

\author{
Jiang Jianyong \\ Panyapiwat Institute of Management, Nonthaburi, Thailand
}

Since the 1990s, internationalization of the traditional Chinese medicine (TCM) has been receiving growing popularity among the general public. International education in the field of TCM has also contributed to the internationalization of TCM with its long history and broader impacts outside China. The international education in traditional Chinese medicine has greatly promoted traditional Chinese medicine overall. However, there are only a few scientific studies on the mechanisms, development logic and evolution path in this field. This paper carries out the empirical analysis based on the literature to explain the research significance, putting forward the policy suggestions, and discussing the directions for further research.

Keywords: traditional Chinese medicine; international education; strategic alliance; brand awareness

\section{Introduction}

China is obviously the motherland of traditional Chinese medicine, most of teachers in colleges, universities and other institutions teaching traditional Chinese medicine (TCM) abroad have graduated or studied in Chinese domestic universities teaching TCM. Also, many foreign educational institutions teaching TCM are involved in various forms of international exchanges and cooperation, establishing strategic alliances with various traditional Chinese medicine education centers.

According to the data from the Ministry of Education and the State Administration of Traditional Chinese Medicine of China, among the 2,956 universities and colleges nationwide (according to the data from Department of International Cooperation of the Ministry of Education of China, as of 2019), 20 TCM colleges and universities have been qualified to enroll foreign students and have more than $40 \%$ of the overseas Chinese students studying TCM in China.

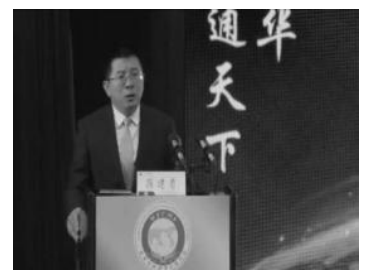

Jiang Jianyong

PhD Student, Chinese Graduate School,

Panyapiwat Institute of Management, Nonthaburi, Thailand.

Research interests: Chinese medicine, economy of medical services, medical market.

E-Mail: 289014728@qq.com 


\section{PERFORMANCE EFFECTS OF COOPERATION AND}

\section{Theoretical basis \& Research Hypothesis}

\section{Cooperation and Competition Intensity between Strategic Alliance (CCISA) and their Performance}

Chandler (1962) applied the SCP model for their analysis of strategic decision-making and introduced the SSP paradigm (Strategy-Structure-Performance) into the field of strategic management.

According to the resource-dependent theory, the foundation of an alliance is always resource-dependent. Harrison et al. (1991) believed that the alliance performance of two enterprises with different but complementary resources would be doing much better. The organizational structure and characteristics of strategic alliances profoundly affect their performance, which, in turn, affects organizational survival.

\section{Cooperation and Competition Intensity of Strategic Alliance and Brand Awareness}

This study conducted a literature review on the influence between strategic alliance and brand awareness, and has found that Axelrod (1984), Prahalad \& Bettis (1986), Barney (1991), Lado \& Wilson (1994), Lado et al. (1992), Parkhe (1993), Chen \& Fan (2007) all suggested that brand awareness of partners should be taken into consideration alliance in the dimension of "when establishing alliances with the input-based competence factor".

According to the resource-based theory and institutional theory, lack of individual resources of the partners may lead to the establishment of an alliance, but brand awareness after alliance and brand awareness of the partners themselves change significantly then. According to the research logic of Lada et al. (1992) and Chen \& Fan (2007), internal characteristics such as composition, stability, cooperation and competition of strategic alliance and other internal contradictions have a strong influence on brand awareness.

\section{Brand Awareness and Performance}

According to the CBBE model as proposed by (Keller, 2001), the basic logical relationship of "brand awareness - brand association, perceived quality - brand emotion brand loyalty (attitude loyalty and behavior loyalty)" exists in all the dimensions of brand equity. According to the classification of brand equity by Aaker and Keller, brand awareness belongs to the primary brand performance and directly affects senior brand performance.

Focusing on brand awareness as a variable, this paper aims to exploit the underlying operating logic of the international education market in the field of TCM as a primary market with the basic position of brand awareness.

From the perspective of organizational brand internalization, this paper studies the internal and external balance of brand management and the dominant factors driving organizational internalization, formation of customer preference and customer loyalty, thus affecting performance (Betts, 1999; Gapp \& Merrilees, 2006).

The theoretical model of our study is presented in Fig. 1.

According to the resource-dependent theory, members of the international TCM education alliance must stimulate the development of this alliance through both cooperation and competition, seeking new stability, and thus promoting the performance of the alliance partners.

According to the structural contradictions inside strategic alliances, the principle of reciprocity and market power leading to social identity and trust (Das and Teng, 1998) 
mutual understanding may be achieved with better coordination of the resource allocation and contribution, stimulation of value creation, and reduction of risks arising from opportunism, namely, by establishing trust and personal relationship (Das and Teng ,1998; Bouncken et al., 2016).

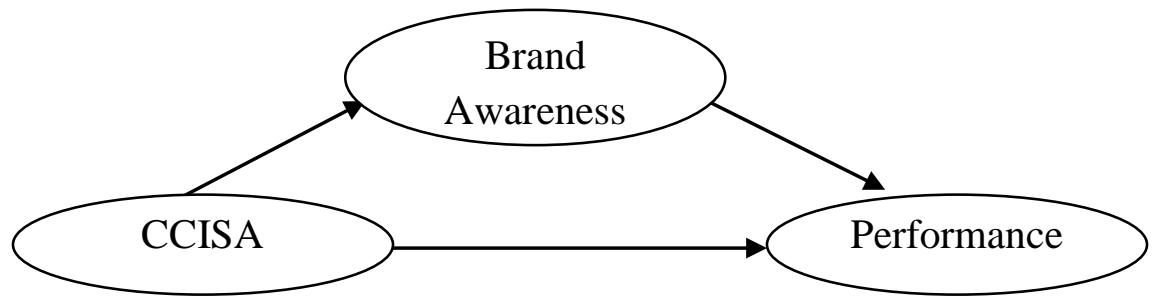

Figure1 - Theoretical Model

(made by the author)

Moderating the intensity of both cooperation and competition inside an alliance may also create and capture value (Peng et al., 2020), while "reciprocity determines the coalition to seek "mutual commitment between partners with complementary resources" (Gnyawali \& Park, 2009). Through participation and interaction, coalition partners deepen and expand their cooperation relationship, thus, mutual trust is gradually developed (Kogut \& Zander, 1992). Eventually, this would reduce transaction costs, improve performance of the alliance partners, and also reduce the opportunistic risks. This reduction of hidden costs thanks to internal alliance maintenance also stimulates long-term performance of the alliance partners. Based on the theoretical analysis above, the following hypothesis is proposed:

H1: Cooperation and competition intensity inside strategic alliances are positively correlated with alliance performance.

Hudson (2013) believed that the importance of brand awareness is reflected in its ability to influence consumers' purchases. For the international market of TCM, brand awareness is reflected in the increase of the patients number (or the audience) and the expansion of market share, so as to realize the brand awareness of the international education alliance of TCM and promote both quality and quantity of the market.

The incentive effect on brand awareness from the cooperation and competition intensity of strategic alliance may be derived from the endogenous motivation of the alliance structure and the principle of resource benefit and reciprocity.

Therefore, under the effect of social exchange theory, the principle of reciprocity induces the incentive of institutional theory so that the strategic alliance will inevitably stimulate the performance through the formation of brand awareness, so as to obtain greater benefits.

The forming process of the alliance's brand awareness depends on the internal balance degree of the intensity of cooperation and competition inside the strategic alliance and the degree of effective use of resources. Following the institutional theory, through both pressure and incentives, the formation and promotion of brand awareness have both theoretical and practical demand. Based on the theoretical analysis above, the following hypothesis can be proposed:

H2: The cooperation and competition intensity inside the strategic alliance are positively correlated with brand awareness. 


\section{PERFORMANCE EFFECTS OF COOPERATION AND}

Brand awareness influences consumers' product attitude and purchase intentions through communication effect (Rossiter \& Percy, 1987), so that even if consumers are not familiar with the product but it has a high level of visibility, it is still possible to stimulate purchases. Organizational performance is a multidimensional variable (Davison \& Honig, 2003), and it is often divided into short-term and long-term performances: short-term performance is measured by financial performance, while long-term performance is measured by competitive advantage (Fang \& Zou, 2009; Siguaw et al., 1998; Homburg et al., 2010). Given the industry characteristics of a long investment cycle and slow effect of education products, the purpose of improving brand awareness at the international education market of TCM is not only to expand the market share, but more importantly, to focus on long-term competitive advantage which directly affects performance. Homburg regards brand awareness as a core brand indicator, which is an important source of customer perception of brand equity ( $\mathrm{Lu}$ et al, 2016), while performance is the concrete embodiment and a consequence of brand equity. Performance is the result of incentive induction after the formation of brand awareness which stimulates performance under the influence of pressure effect. Based on the theoretical analysis above, the following hypothesis can be proposed:

\section{H3: Brand awareness is positively correlated with performance.}

Xu Erming (2012) proposed that "the relationship between resource complementarity and opportunism is an inverted U-shaped relationship". To solve this contradiction effectively, it is necessary to use the resource complementarity ability of the alliance to improve common benefits (Messick et al., 1983) and also improve or maintain the competitive position (Grimm \& Smith, 1997), reducing the costs for alliance partners, strengthening the alliance's transparency internally, and continuously improving brand awareness externally, so as to improve financial and organizational performance of the alliance, achieving strategic flexibility and control (Sutton \& Aunno, 1989). Dyer (2018) proposed that "changes in the external environment will affect the interaction between cooperation and competition". When brand awareness affects the original external environment of an alliance, it will inevitably have an impact on cooperation and competition inside the alliance, thus affecting its overall performance. From these theoretical deductions, it can be clearly seen that the enhanced qualities of an alliance improve its market share and other performance indicators by continuously improving brand awareness, thus increasing the total volume of resource allocation. Based on the theoretical analysis above, the following hypothesis can be proposed:

H4: Brand awareness plays the mediating effect between cooperation and competition intensity of strategic alliances and their performance.

\section{Research Methodology}

\section{Research Tools}

In this paper, SPSS25.0 has been used for exploratory factor analysis, while Cronbach's Alpha coefficient and principal component analysis were used to test reliability and validity of the questionnaire. Mplus 7.4 has been used for confirmatory factor analysis (CFA) to test the internal structure consistency and the correlation between the latent variables, and the structure fitting degree of the scale, as well as CR and AVE. 
The core indicators were counted to test the dimension reliability, convergence validity and discriminant validity of the questionnaire, so as to be prepared for further hypothesis testing. This study also adopts SPSS25.0 for correlation analysis, which is mainly used by researchers to reveal the strength of statistical relationship between variables, and mainly uses correlation analysis technology to test the correlation between the key variables such as performance, brand awareness, cooperation and competition intensity of the strategic alliances.

In this study, the statistical three-step method has been used to conduct the analysis. And mature scales have been used to measure the variables in the design of questions suggested for the questionnaire. The main variable concept and maturity scales are all from the top journals, including the SCI-indexed ones. These scales have been used repeatedly by researchers in different research settings and have been proven to be highly stable and accurate when it comes to measurement of various variables.

\section{Research object}

In this survey, 254 questionnaires have been collected by using the questionnaire. After the unqualified questionnaires were removed, 117 samples were left, all being from $26 \mathrm{TCM}$ colleges and universities, foreign participating institutions of TCM international education and natural persons. The institutions involved cover more than 20 universities of TCM in China that organize and perform international TCM education.

Table 1 - Descriptive statistics of the sample's dimensions (made by the author)

\begin{tabular}{|l|c|c|c|c|c|c|c|}
\hline \multicolumn{1}{|c|}{ Variable } & $\mathrm{N}$ & Mean(E) & $\begin{array}{c}\text { Standard } \\
\text { Deviation }\end{array}$ & Variance & Skewness & Kurtosis & Median \\
\hline Performance & 117 & 5.439 & 1.023 & 1.047 & -0.317 & -0.518 & 5.667 \\
\hline Brand Awareness & 117 & 5.094 & 1.220 & 1.489 & -0.262 & -0.381 & 5.000 \\
\hline CCISA & 117 & 6.548 & 1.185 & 1.403 & -0.028 & -0.080 & 6.714 \\
\hline
\end{tabular}

According to Kline (1998), the criteria for assessing the descriptive statistics usually are: the absolute value of skewness is less than 3, the absolute value of kurtosis is less than 10 , thus indicating that the item data of measurement variables basically present the normal distribution.

The test results show that the CA \& KMO values of the questionnaire are 0.934 , and the $\mathrm{P}$ value is significant, thus indicating that the questionnaire has good reliability and structural validity.

\section{Data Analysis}

\section{Confirmatory Factor Analysis}

MPLUS 7.4 software has been used to calculate the relevant degree of fit on the relevant parameters of the model by using the maximum likelihood method, as shown in Fig. 2. 


\section{PERFORMANCE EFFECTS OF COOPERATION AND}

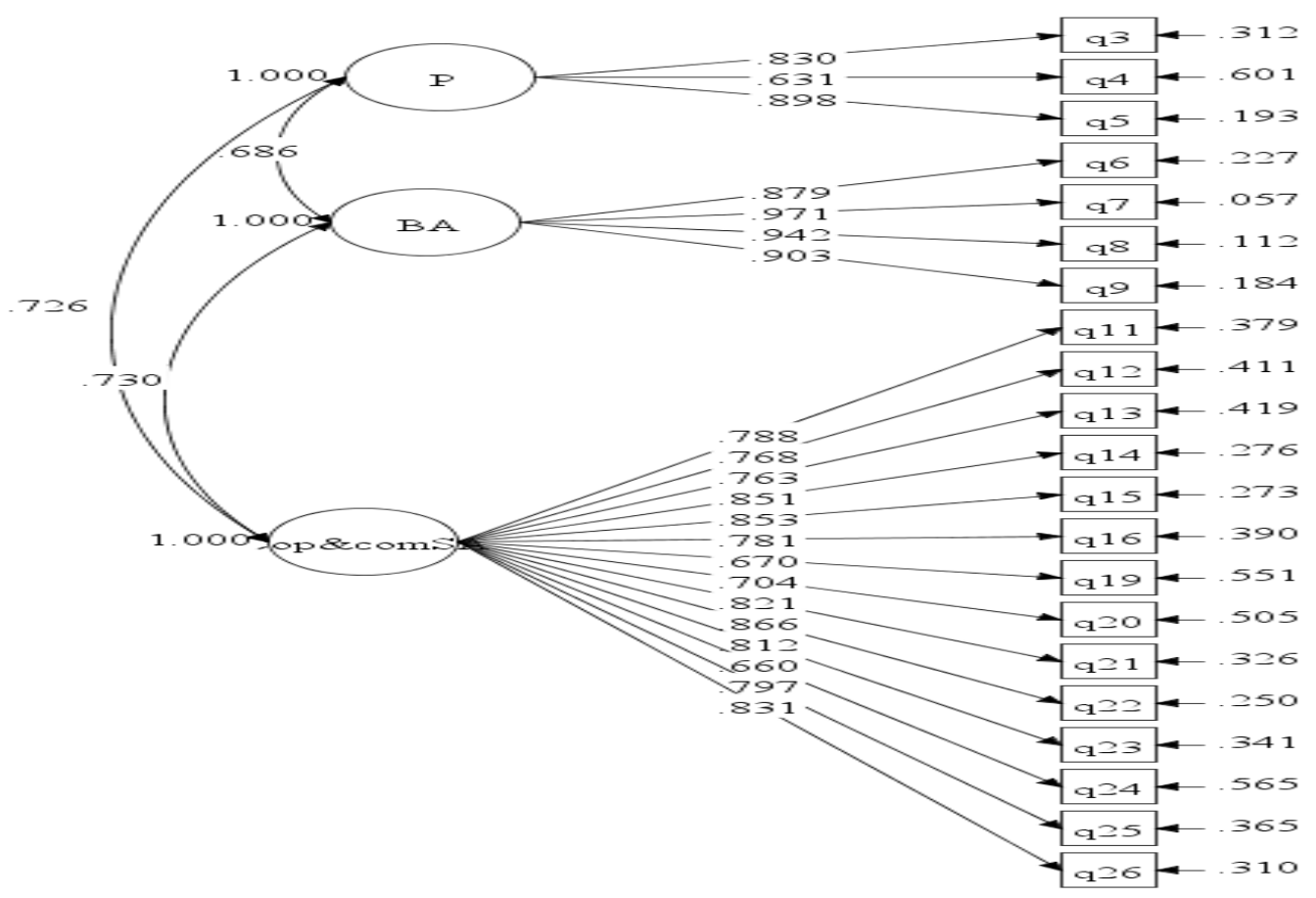

Figure 2 - Confirmatory Factor Analysis

(made by the author)

Table 2. Confirmatory Factor Analysis

(made by the author)

\begin{tabular}{|l|c|c|c|c|}
\hline \multicolumn{1}{|c|}{ Variables } & $\mathrm{P}$ & $\mathrm{CA}$ & $\mathrm{CR}$ & AVE \\
\hline $\mathrm{P}$ & $* * *$ & 0.832 & 0.834 & 0.794 \\
\hline BA & $* * *$ & 0.959 & 0.959 & 0.925 \\
\hline CCISA & $* * *$ & 0.957 & 0.957 & 0.785 \\
\hline
\end{tabular}

The Model fit index results are as follows: $x^{2} / d f=2.034, \mathrm{TLI}=0.904, \mathrm{CFI}=0.915$, $\mathrm{SRMR}=0.050, \mathrm{RMSEA}=0.094$. This indicates that the measurement model of this study fits well, all the variables are well-differentiated and all the indicators meet the requirements.

\section{Correlation Analysis}

Tab. 3 shows that there is a significantly positive correlation between performance, brand awareness and CCISA, and also reports the influence of the control variables. 
Table 3 - Correlation Coefficient Matrix for Each Variable (made by the author)

\begin{tabular}{|c|c|c|c|c|c|c|}
\hline & $\mathrm{P}$ & $\mathrm{BA}$ & $\mathrm{CCISA}$ & $\begin{array}{c}\text { Type of } \\
\text { partner }\end{array}$ & $\begin{array}{c}\text { Service } \\
\text { duration }\end{array}$ & $\begin{array}{c}\text { Business } \\
\text { duration }\end{array}$ \\
\hline Performance (P) & 1 & & & & & \\
\hline $\begin{array}{c}\text { Brand Awareness } \\
\text { (B) }\end{array}$ & $0.621^{* *}$ & 1 & & & & \\
\hline CCISA & $0.617^{* *}$ & $.700^{* *}$ & 1 & & & \\
\hline Type of partner & 0.085 & 0.003 & -0.013 & 1 & & \\
\hline Service duration & 0.003 & 0.015 & 0.012 & 0.067 & 1 & \\
\hline Business duration & -0.027 & 0.082 & -0.019 & 0.138 & $0.411^{* *}$ & 1 \\
\hline
\end{tabular}

Note : **refers to a 0.01 level (double tail) significant correlation

Table 4 - Collinearity of Brand Awareness with Cooperation and Competition Intensity inside Strategic Alliance

(made by the author)

\begin{tabular}{|c|c|c|c|c|c|c|c|c|}
\hline \multicolumn{2}{|c|}{} & \multicolumn{2}{c|}{$\begin{array}{c}\text { Non- } \\
\text { normalized } \\
\text { coefficients }\end{array}$} & \multicolumn{2}{c|}{$\begin{array}{c}\text { standardized } \\
\text { coefficient }\end{array}$} & \multicolumn{2}{c|}{$\begin{array}{c}\text { collinearity } \\
\text { statistics }\end{array}$} \\
\hline \multirow{2}{*}{ Variable } & Variable & B & $\begin{array}{c}\text { standard } \\
\text { error }\end{array}$ & Beta & t & Significance & Tolerance & VIF \\
\hline \multirow{2}{*}{ B A } & Constant & 0.373 & 0.456 & & 0.816 & 0.416 & & \\
\cline { 2 - 10 } & CCISA & 0.721 & 0.069 & 0.7 & 10.51 & 0 & 1 & 1 \\
\hline
\end{tabular}

Table 5 - Collinearity between performance and brand awareness, Cooperation and Competition Intensity of Strategic Alliance

(made by the author)

\begin{tabular}{|c|c|c|c|c|c|c|c|c|}
\hline \multicolumn{2}{|c|}{} & \multicolumn{2}{c|}{$\begin{array}{c}\text { Non-normalized } \\
\text { coefficients }\end{array}$} & \multicolumn{2}{c|}{$\begin{array}{c}\text { standardized } \\
\text { coefficient }\end{array}$} & \multicolumn{2}{c|}{$\begin{array}{c}\text { collinearity } \\
\text { statistics }\end{array}$} \\
\hline \multirow{2}{*}{ Variable } & Variable & B & $\begin{array}{c}\text { standard } \\
\text { error }\end{array}$ & Beta & $\mathrm{t}$ & Significance & Tolerance & VIF \\
\hline \multirow{3}{*}{$\mathrm{P}$} & Constant & 1.83 & 0.4 & & 4.577 & 0 & & \\
\cline { 2 - 10 } & CCISA & 0.309 & 0.084 & 0.358 & 3.682 & 0 & 0.51 & 1.961 \\
\cline { 2 - 10 } & BA & 0.311 & 0.081 & 0.371 & 3.82 & 0 & 0.51 & 1.961 \\
\hline
\end{tabular}

\section{Hypotheses Testing}

\section{Main effect test}

In this study, the scale of partners, service length (alliance experience) and business length (alliance cooperation time) have been included as the controlled variables. After further verification of the model by means of using MPLUS 7.4 software, results presented visually in Fig. 3 have been obtained. 


\section{PERFORMANCE EFFECTS OF COOPERATION AND}

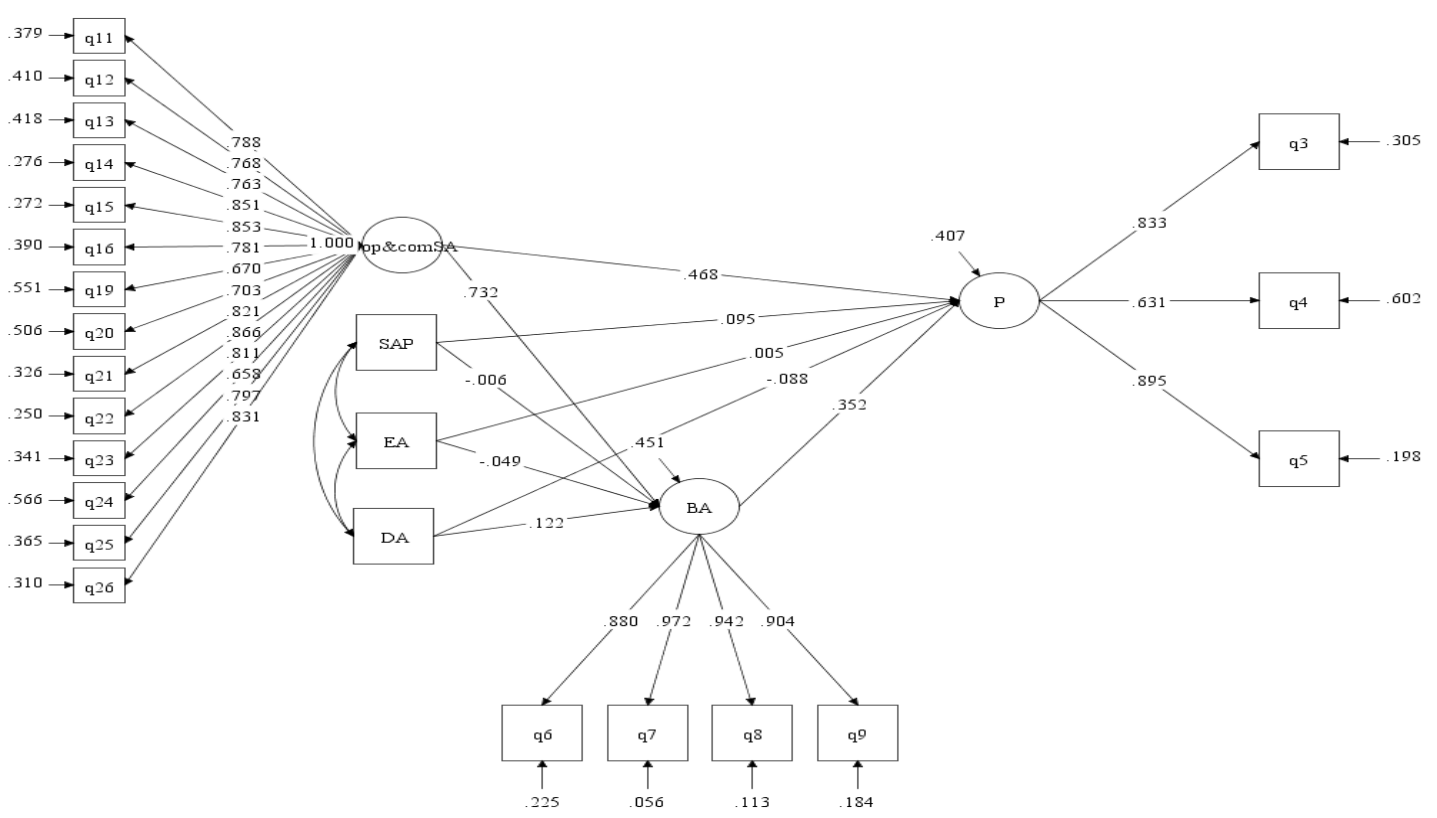

Legend : SAP — StratagicAllicance Partner; EA — Alliance Experience; DA — Alliance Duration.

Figure 3 - Intermediary Model Diagram of the Structural Equation (controlled variables included)

(made by the author)

Table 6 - Model fitting index

(made by the author)

\begin{tabular}{|c|c|c|c|c|c|}
\hline & $\chi^{2} / \mathrm{df}$ & CFI & TLI & RMSEA & SRMR \\
\hline Reference values & $<3$ & $>0.9$ & $>0.9$ & $<0.08$ & $<0.08$ \\
\hline Actual values & 1.777 & 0.917 & 0.906 & 0.081 & 0.05 \\
\hline Decision & $\mathrm{Y}$ & $\mathrm{Y}$ & $\mathrm{Y}$ & $\mathrm{Y}$ & $\mathrm{Y}$ \\
\hline
\end{tabular}

The comparison between Fig. 2 and 3 shows that when the control variables are added to the model, the RMSEA value of the model is adjusted from 0.094 to 0.081 , thus indicating that the model is more significant after the control and suggesting that the main effect of the model is established.

Table 7 - Relationships between the dimensions (made by the author)

\begin{tabular}{|c|c|c|c|c|c|c|}
\hline & Coef. & Std.Err & $\mathrm{t}$ & \multicolumn{2}{|c|}{$\mathrm{P}>|\mathrm{t}|$} & \multicolumn{2}{|c|}{$95 \%$ Conf. Interval } \\
\hline $\mathrm{CCISA} \rightarrow \mathrm{P}$ & 0.468 & 0.105 & 4.466 & 0.000 & 0.213 & 0.780 \\
\hline $\mathrm{BA} \rightarrow \mathrm{P}$ & 0.352 & 0.107 & 3.285 & 0.001 & 0.014 & 0.620 \\
\hline $\mathrm{CCSIA} \rightarrow \mathrm{BA}$ & 0.732 & 0.046 & 15.950 & 0.000 & 0.607 & 0.823 \\
\hline
\end{tabular}


Tab. 7 shows that the $P$ values among the latent variables are all less than 0.05 , which is significant at the 0.05 significance level. All the $\mathrm{T}$ values are greater than 2 , so all the hypotheses in this study are valid.

\section{Hypotheses testing for the mediating effect}

Table 8 - The mediating effect of brand awareness on cooperation and competition intensity of strategic alliance and performance

(made by the author)

\begin{tabular}{|c|c|c|c|c|c|c|}
\hline & Coef. & Std.Err & $\mathrm{t}$ & $\mathrm{P}>|\mathrm{t}|$ & \multicolumn{2}{|c|}{$95 \%$ Conf. Interval } \\
\hline $\mathrm{CCISA} \rightarrow \mathrm{P}$ & 0.468 & 0.105 & 4.466 & 0.000 & 0.213 & 0.780 \\
\hline $\mathrm{BA} \rightarrow \mathrm{P}$ & 0.352 & 0.107 & 3.285 & 0.001 & 0.014 & 0.620 \\
\hline $\begin{array}{c}\mathrm{CCISA} \rightarrow \text { Brand } \\
\text { awareness }\end{array}$ & 0.732 & 0.046 & 15.950 & 0.000 & 0.607 & 0.823 \\
\hline
\end{tabular}

Table 9 - Direct and indirect effects

(made by the author)

\begin{tabular}{|l|c|c|c|c|c|c|}
\hline & Coef. & Std.Err & $\mathrm{t}$ & \multicolumn{2}{|c|}{$\mathrm{P}>|\mathrm{t}|$} & \multicolumn{2}{|c|}{$95 \%$ Conf. Interval } \\
\hline $\mathrm{CCISA} \rightarrow \mathrm{BA} \rightarrow \mathrm{P}$ & 0.258 & 0.080 & 3.218 & 0.001 & 0.013 & 0.447 \\
\hline $\mathrm{CCISA} \rightarrow \mathrm{P}$ & 0.468 & 0.105 & 4.466 & 0.000 & 0.213 & 0.780 \\
\hline total effect & 0.726 & 0.053 & 13.782 & 0.000 & 0.586 & 0.836 \\
\hline
\end{tabular}

Tab. 8 and 9 show that each path of the mediation model reaches significance at the 0.05 significance level. After bootstrap sampling, the confidence interval does not contain 0 .

When the dependent variable was regressed for both the intermediary variable and the independent variable, the indirect effect path coefficient was 0.258 , and the corresponding $\mathrm{t}$ value was 3.218, thus reaching significance at the significance level of 0.05 , while the confidence interval did not contain 0 . Combined with the significance of other paths, it could be seen that $\mathrm{H} 4$ is valid. Therefore:

H4. Brand awareness plays a partial mediating role in the relationship between cooperation intensity and performance of strategic alliances.

\section{Conclusion and Discussion}

\section{Research Conclusions. Theoretical contribution \& management implications}

All the five initially put forward hypotheses are proved to be true through empirical analysis and hypothesis testing. The results of our empirical research are discussed below.

The research hypotheses have been proved to be positive, with the following significance. As an important carrier of traditional Chinese medicinal culture, international strategic alliances in the field of TCM education combine the typical characteristics of cultural communication, humanistic communication and medical communication. 


\section{PERFORMANCE EFFECTS OF COOPERATION AND}

Therefore, it is necessary to study the international development of traditional Chinese medicine.

There is very little research available on the internal operation mechanisms, development pathways and trends in TCM internationalization.

This paper explains the strategic alliance mechanisms, thus refining and enriching the research on strategic alliances overall, highlighting the theoretical value and the laws of development in the field of TCM international education specifically. Strategic alliances are proved to be advantageous for the international education in TCM.

The intensity of cooperation and competition between such alliances determines their internal structure which usually follows the relevant laws.

Cooperation and competition between these alliances can be presented as an inverted U-shaped structure, with several different stages. The alliance partners must make appropriate structural adjustments which, in their turn, would positively affect the performance.

This change in an organizational form may be then externalized into brand equity and finally produce results. This is an actual breakthrough in the traditional development path that has a strong theoretical and practical guiding significance.

\section{Limitations and Prospects}

There is obviously a lack of effective measurement scale here, which could have been applied to the international education market in traditional Chinese medicine to measure the intangible heritage which is deeply influenced by national policies and laws.

Due to the time and effort constraints, this article has not been developed enough, some of the research dimensions may require further verification.

In our view, the research should have collected about 20 times the number of the questionnaires collected.

However, due to the epidemic situation, the researchers could not obtain more questionnaires through face-to-face persuasion, and this has resulted in a serious shortage in the number of questionnaires. This may have partially led to certain deviations in both the sample and the conclusions. This needs to be improved at later stage and further research in the same direction.

\section{References}

Axelrod, R. (1984). The Evolution of Cooperation, New York: Basic Books.

Barney, J. B. (1991). Firm resources and sustained competitive advantage. Journal of Management, 17, 99-120.

Betts, M. (1999). Brand Competence, Strategic Communication Management, 3, 4, 10-16.

Bouncken, R. B., Clau B. T. \& Fredrich, V. (2016). Product Innovation Through Coopetition in Alliances: Singular or Plural Governance? Industrial Marketing Management, 53, 77-90.

Chandler, A. D. (1962). Strategy and Structure: In: History of the Industrial Enterprise. Cambridge, Massachusetts: MIT Press. 
Das, T. K. \& Teng, B. S. (2001). Trust, control, \& risk in strategic alliances: An integrated framework. Organization Studies, 22, 2, 251.

Das, T. K. \& Teng, B. S. (2003). Partner analysis \& alliance performance. Scandinavian Journal of Management, 19, 279-308.

Dyer, J. H. \& Nobeoka, K. (2000). Creating \& managing a high performance knowledge-sharing network: The Toyota case. Strategic Management Journal, 21, 345-367.

Fang, E. \& Zou, S.M. (2009). Antecedents and Consequences of Marketing Dynamic Capabilities in International Joint Ventures. Journal of International Business Studies, 40, 5, 742-761.

Gapp, R. \& Merrilees, B. (2006). Important Factors to Consider When Using Internal Branding as A Management Strategy: A Healthcare Case Study. Brand Management, 14, 162-176.

Gnyawali, D. R. \& Park, B. J. (2009). Co-opetition and Technological Innovation in Small and Medium-sized Enterprises: A Multilevel Conceptual Model, Journal of Small Business Management, 47, 308-330.

Hitt, M. A., Harrison, J. S. \& Irel, R. D. (2001). Mergers \& Acquisitions: A Guide to Creating ValueFor Stakeholders. Oxford University Press.

Homburg, C., Klarmann, M., \& Schmitt, J. (2010). Brand awareness in business markets: When is it related to firm performance? International Journal of Research in Marketing, 27, 3.

Hudson, B. T. \& Balmer, J. (2013). Corporate Heritage Brands: Mead's Theory of the Past, Corporate Communications, 18, 3, 347-361.

Keller, K. L. (1993). Conceptualizing, measuring, and managing customer-based brand equity. Journal of Marketing, 57, 1, 1-22.

Kogut, B. \& Zander, U. (1992). Knowledge of the Firm, Combinative Capabilities and the Replication of Technology. Organization Science, 3, 3, 383-397.

Lado A. A. et al. (1992). A competency - based model of sustainable competitive advantage: toward a conceptual integration. Journal of Management, 8, 1, 77-91.

Lado, A. \& Wilson, M. (1994). Human resource systems and sustained competitive advantage: A competency- based perspective, The Academy of Management Review, 19, 4, 699-727.

Lu, H. L. et al. (2016. Research on the impact of B2B branding on inter enterprise relationship and financial performance. Nankai Business Review, 19, 4, 169-180.

Messick, D.M., Wilke, H., Brewer, M.b., Kramer, R.M., Zemke, P.E., \& Lui, L. (1983). Individual adaptations and structural-change as solutions to social dilemmas. Journal of Personality \& Social Psychology, 44, 2, 294-309.

Parkhe, A. (1993). Strategic alliance structuring: a game theoretic and transaction cost examination of interfirm cooperation. Academy of Management Journal, 36, 4, 794-829.

Peng, Z. Z. et al. (2020. Research on the relationship between alliance competition and cooperation, governance mechanism and innovation performance in the dynamic environment, Management World, 3, 205-233.

Prahalad, C.K. \& Bettis, R. (1986). The dominant logic: A new linkage between diversity and performance. Strategic Management Journal, 7, 485-501.

Rossiter, J.R. \& Percy, L. (1987). Advertising and Promotion Management, Singapore, McGraw-Hill. 


\section{PERFORMANCE EFFECTS OF COOPERATION AND}

Sutton, R. I. \& Aunno, T. D. (1989). Decreasing organizational size: untangling the effects of money and people. The Academy of Management Review, 14, 2, 194-212.

$\mathrm{Xu}$, E.M. \& Xu, K. (2012). The impact of resource complementarity on opportunism and strategic alliance performance. Managing the World, 1.

Paper submitted

Paper accepted for publishing

Paper published online
11 January 2021

25 February 2021

30 November 2021 